\title{
Food Restriction and the Accumulation of Fat in the Livers of Wistar Rats
}

\author{
Leandro P. de Moura*\#,1, Marcelo Costa Júnior ${ }^{\#, 1}$, Rodrigo A. Dalia ${ }^{\#, 1}$, Michel B. de Araújo ${ }^{\#, 1}$, \\ Ismael F. Freitas Júnior ${ }^{\#, 2}$ and Maria A. R. de Mello ${ }^{\#, 1}$ \\ ${ }^{1}$ Laboratory of Nutrition, Metabolism and Exercise, Department of Physical Education, Universidade Estadual Paulista \\ (UNESP), $24^{a}$ avenue $n^{\circ} 1515$, P.O. Box 199, Bela Vista, Rio Claro, SP, Brazil \\ ${ }^{2}$ Department of Physical Education, Universidade Estadual Paulista (UNESP), Roberto Simonsen Street, 305, \\ Presidente Prudente, SP, Brazil
}

\begin{abstract}
Laboratory rats, when kept in conditions regarded as "standard", are physically inactive, do not have proper environmental stimulation and have free access to food, which can lead to metabolic syndrome and fat accumulation in the liver. This study aimed to analyse the susceptibility of "control animals", which have free access to food, to metabolic syndrome and fat accumulation in the liver compared to animals that were subjected to food restriction. Ninety-day-old Wistar rats were divided into two groups, fed ad libitum (free access to food) and food restricted (60\% of the amount of food consumed by the ad libitum group), according to a protocol of alimentation for four weeks. To analyse the effects of food restriction on the nutritional status, serum albumin and total protein levels were analysed and showed no differences between groups, which indicated an absence of malnutrition. The retroperitoneal, subcutaneous and mesenteric fat tissues were weighed, and it was found that the mesenteric fat tissue showed a greater reduction from the food restriction. There was no difference in the insulin sensitivity and the fat accumulation in the liver between groups. However, it was shown that for every $1 \%$ decrease in weight due to the food restriction, insulin sensitivity increased by $0.67 \%$ and hepatic fat decreased. Therefore, we can conclude that caloric restriction leads to weight loss. Although no significant differences in insulin sensitivity and hepatic fat content existed between the groups at the end of the experiment, weight loss modulated these variables.
\end{abstract}

Keywords: Food restriction, Nonalcoholic fatty liver disease, Rats.

\section{INTRODUCTION}

The accumulation of fat in the liver is a disease characterised by the presence of fat droplets in the organ [1] and discovered by Ludwig et al., in 1980 [2]. This accumulation can vary from a simple steatosis without evidence of inflammation to necro-inflammatory manifestations, including nonalcoholic hepatitis that may progress to fibrosis in $50 \%$ of cases, to cirrhosis in $15 \%$ of cases and to liver failure in $3 \%$ of cases [3-7]. This framework is found in 57.5 to $75 \%$ of obesity cases [5] due to changes such as increased consumption of fat and decreased secretion of lipids by the liver [8] or by other mechanisms such as oxidative stress, an inflammatory response and insulin resistance (IR) $[9,10]$.

Increased caloric intake is directly related to the development of insulin resistance [11]. This imbalance in energy consumption leads to obesity, and in 1988, Reaven [12] was among the first to associate the hypertrophy of adipose tissue, commonly found in obese patients, with IR. One of the ways obesity causes IR is through the action of the fraction of the saturated fatty acids that impairs the transduction of the insulin signalling pathway causing protein kinases to be

*Address correspondence to this author at the Department of Physical Education, Universidade Estadual Paulista (UNESP), Avenida $24^{\mathrm{a}} \mathrm{n}^{\circ}$ 1515, P.O. Box 199, Bela Vista, Rio Claro, Zip code: 13506-900, SP, Brazil; Tel: +55(19)8197-9999; Fax: +55(19)3534-0009;

E-mail:mellomar@rc.unesp.br

${ }^{\#}$ These authors contributed equally to this work. serine-phosphorylated [13]. For an improved quality of life, the main changes include regular participation in physical activity and calorie restriction [14-16].

Because there are limitations on research using humans, animal models have become very important study tools in several areas of science. Mice and rats are widely used as animal models in biomedical research, including the field of nutrition, which uses about $90 \%$ of all research animals. When housed in conditions regarded as "standard" in most laboratories, these rodents are sedentary, have continuous access to food and do not have adequate environmental stimulation [17]. Therefore, it is questionable whether these animals are adequate "controls" for studies involving altered nutritional states.

Compared with animals that exercise and are properly stimulated, these animals used as a "control" are relatively overweight, insulin-resistant and hypertensive $[18,19]$. In fact, a simple reduction of daily food intake to $20-40 \%$ below that of ad libitum consumption or by feeding intermittently rather than continuously was effective in significantly reducing the risk of chronic degenerative diseases such as cancer, type 2 diabetes and kidney disease and prolonged the life span of laboratory rats and mice by $40 \%$ without causing malnutrition [20-24].

Food restriction is an important tool to minimise the incidence of obesity and its consequences $[25,26]$, and there are few studies in the literature analysing the liver responses of Wistar rats subjected to caloric restriction; therefore, this 
study aimed to analyse the susceptibility of control animals to obesity, IR and hepatic fat accumulation compared to animals that were subjected to dietary restriction.

\section{MATERIALS AND METHODS}

\section{Animals and Treatment}

The study used 20 Wistar rats (90 days old), which came from the Central Vivarium (Bioterio Central) of UNESPat the Botucatu Campus, that were maintained in the vivarium of the biodynamic laboratory of the Department of Physical Education, Biosciences Institute of UNESP, Rio Claro Campus. The animals were housed in polyethylene cages (five animals per cage) and kept at a controlled room temperature of $23 \pm 1^{\circ} \mathrm{C}$, with a photoperiod of 12 hours of light/12 hours of dark with water provided ad libitum. The experiment was conducted in accordance with the current Brazilian legislation and standards of the Brazilian College of Animal Experimentation (Colégio Brasileiro de Experimentação Animal-COBEA). All standards were adhered to rigorously. The use of animals in this study was approved by the ethics committee at the Biosciences Institute at UNESP, Rio Claro (Process: 2011/6274).

\section{Experimental Groups and Design}

The animals were separated into two groups (10/group), ad libitum (AL) and food restriction (FR), according to a four-week feeding protocol.

The ad libitum group of animals had free access to food, and the food intake was recorded daily. The food restriction group was offered food in a quantity corresponding to $60 \%$ of the average amount consumed by the ad libitum group during the previous day. This protocol was designed to cause dietary restriction without malnutrition [21]. All animals in both groups had free access to water.

\section{Insulin Tolerance Test - ITT}

There were previous studies from our research group in wich insulin sensitivity was evaluated by the insulin tolerance test (ITT), pointing interesting results [27,28]. Therefore, in this study insulin sensitivity was evaluated through an ITT. This test was performed at the end of the experiment. An initial blood sample was obtained by making a cut at the end of the animals' tails (time 0). An insulin solution, at a dose of $150 \mathrm{mU} / 100 \mathrm{~g}$ body weight, was then administered through an intraperitoneal injection. New blood samples were obtained after $4,8,12,16$, and 20 minutes using heparinised capillaries calibrated to $25 \mu \mathrm{L}$ for determining the glucose concentrations by using commercial kits (Labor$l a b^{(B)}$. A single cut at the end of the tail was sufficient for all sample collections. The results were analysed by calculating the glucose removal rate (KITT). KITT was expressed as $\% /$ minute and was calculated using the formula $\left(0.0693 / \mathrm{t}_{1 / 2}\right)$ $\mathrm{x}$ 100. Glucose removal $\left(\mathrm{t}_{1 / 2}\right)$ was calculated by a least squares analysis of the curve of the blood glucose levels during the period of insulin decay following its administration [29] by using the Origin 6.0 software.

\section{Evaluation of the Nutritional State}

During the experimental period, the body weight of both groups and the food intake of the ad libitum group were recorded daily. At the end of the experiment, all animals were killed by decapitation after anaesthesia with $\mathrm{CO} 2$. Blood samples were collected for the measurement of total protein and albumin levels and the liver was used for the measurement of triglycerides [30] for the biochemical evaluation of the nutritional status.

\section{Statistics}

The results were expressed as means \pm standard deviations and statistically analysed using the Student's t-test with a significance level pre-established at 5\%.

\section{RESULTS}

The animals we subjected to food restriction had a $19.5 \%$ weight loss (Fig. 1), while those fed ad libitum showed a weight gain.

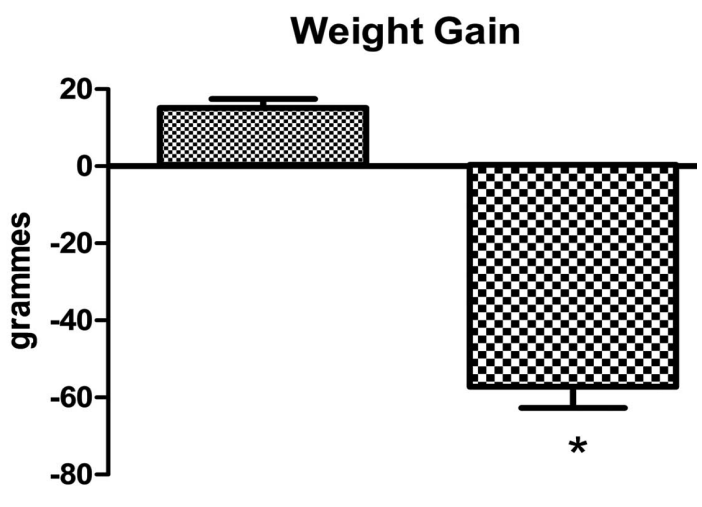

AL $\quad$ FR

Fig. (1). Analysis of weight gain performed by calculating the delta values. Results are expressed as means \pm standard deviation (10 animals/group). $* \neq$ control group.

To evaluate the nutritional status of the animals, the serum concentrations of total protein and albumin were analysed, and it was shown that the caloric restriction protocol used in this study did not cause malnutrition in these animals because they did not differ between groups (Fig. 2).

In relation to insulin sensitivity, there was no difference between the means of the food restricted group when compared to the control group (Fig. 3), but when the loss of weight in relation to insulin sensitivity was analysed, it was found that every $1 \%$ decrease in weight improved insulin sensitivity by $0.67 \%$.

When the weight of adipose tissue from different regions was analysed, it was found that mesenteric fat was the most sensitive depot to the caloric restriction (Fig. 4A); for each $1 \%$ loss in weight, there was a $2.94 \%$ reduction in the mesenteric fat weight. Subcutaneous fat was also reduced in the group subjected to caloric restriction (Fig. 4B). Each 1\% loss in weight caused a $1.49 \%$ decrease in fat. There was also a reduction of retroperitoneal fat (Fig. 4C). For each 1\% loss in total body weight, $2.8 \%$ of retroperitoneal fat was reduced.

The hepatic fat concentration was not different between the groups (Fig. 5), but for each 1\% loss of body weight, body fat in the stock declined $0.67 \%$. 
A Serum Protein

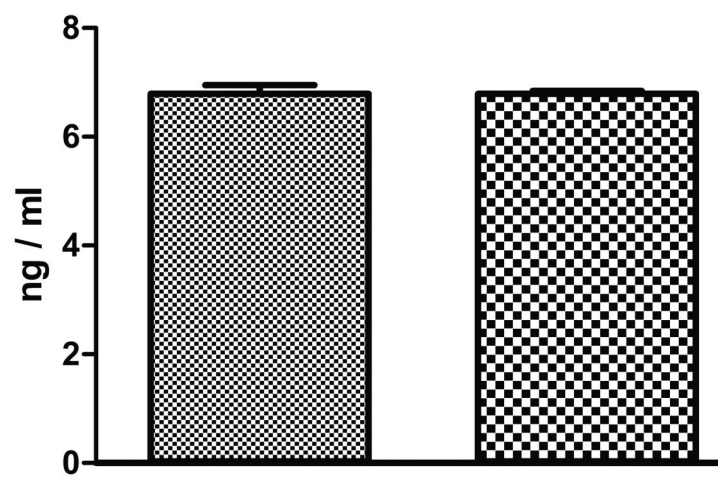

$\mathrm{AL}$

FR

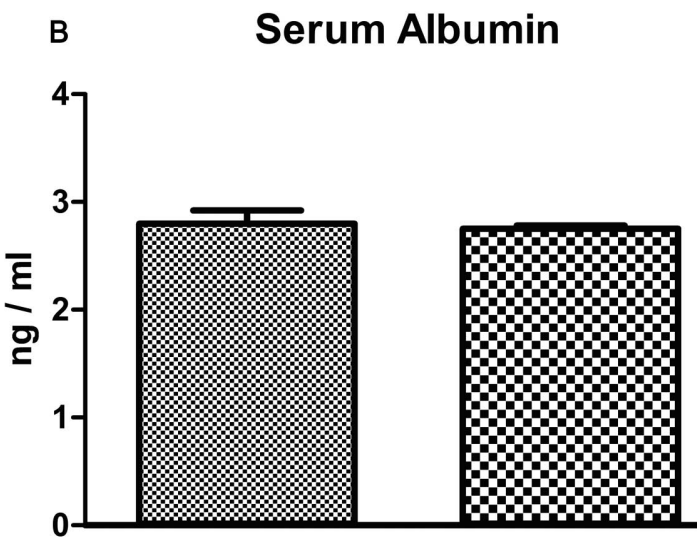

$\mathrm{AL}$

FR

Fig. (2). The serum concentrations of the total protein (A) and albumin (B) at the end of the experiment. Results are expressed as means \pm standard deviation (10 animals/group).

\section{DISCUSSION}

Laboratory rodents are widely used in scientific research and housed in conditions that are considered "standard" in most laboratories, even though these animals are sedentary, have continuous access to food and do not have adequate environmental stimulation [17]. This contributes to the development of hypertension, obesity and IR [18, 19], which directly interferes in research related to nutrition. Therefore, according to the literature $[25,26]$, dietary restriction is necessary to minimise the metabolic changes caused by obesity and IR, but little is known about its effects on the livers of eutrophic rats. In our study, it became clear that dietary restriction (40\%), in addition to reducing the weight gain of animals without causing malnutrition, also contributed to greater insulin sensitivity and less fat accumulation in the liver.

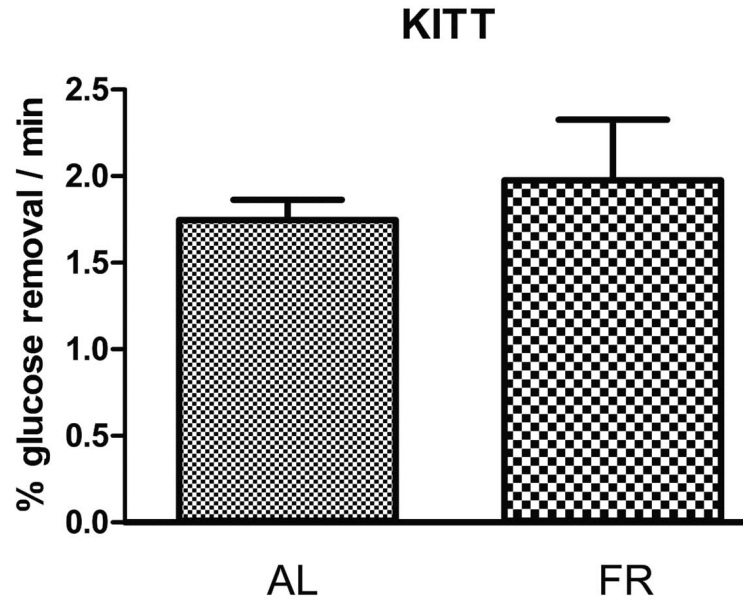

Fig. (3). The removal rate calculated by KITT serum glucose during the insulin tolerance test at the end of the experiment. Results are expressed as means \pm standard deviation (10 animals/group).

To evaluate the nutritional status of the animals, serum albumin and total protein levels were analysed [31-33]. According to the results, the animals subjected to food restriction in the present study showed no evidence of malnutrition because the concentrations of total protein and serum albumin did not decrease.
According to Kraemer et al. [34], the main purpose of food restriction is to minimise the development of obesity. From our results, we note that a $40 \%$ food restriction promoted a $19.5 \%$ decrease of body weight when compared to the ad libitum control animals. According to the literature [33-35], high-energy intake contributes directly to an increased storage of triglycerides in the adipose tissue along with an increase of its final volume. Data related to the total increase in the adipose tissue from calorie availability [3537] were more evident when the weights of adipose tissue from different regions were analysed. Food restriction reduced the weights of the mesenteric, retroperitoneal and subcutaneous adipose tissues by $57.35 \%, 54.63 \%$ and $29.16 \%$, respectively.

The mesenteric fat in our study was the of the most sensitive to the food restriction. Hermsdorff \& Miller [38] showed that the greater susceptibility to a loss of fat tissue located in the visceral region was due to its high vascularity, and the size of their adipocytes indicated a greater response to catecholamines.

The animals with an ad libitum food supply had a higher amount of adipose tissue, specifically the fat tissue in the visceral region, and this increase can be related directly to IR. Various recent research shows that fat tissue has other functions in addition to storing fat $[39,40]$. White adipose tissue is considered an endocrine organ, producing active hormones such as tumour necrosis factor $(\mathrm{TNF}-\alpha)$, resistin, adiponectin and leptin [41]. TNF- $\alpha$ is directly linked to insulin resistance and leads to a reduced insulin-stimulated autophosphorylation of the insulin receptor and a subsequent inhibition of the phosphorylation of insulin receptor substrate-1 (IRS-1). In addition, TNF- $\alpha$ induces changes in the serine phosphorylation of IRS-1, which causes this molecule to inhibit the signalling of the insulin receptor [40]. In our study, we found that in the IR framework, there was a $0.67 \%$ improvement in peripheral insulin sensitivity for every $1 \%$ in weight loss. Our findings corroborate a study by Björntorp [41] that showed that decreases in total mesenteric fat due to dietary restriction can modulate the responses of peripheral tissues to insulin.

The response of peripheral tissues to insulin will interfere directly in the accumulation of fat in the liver because this 

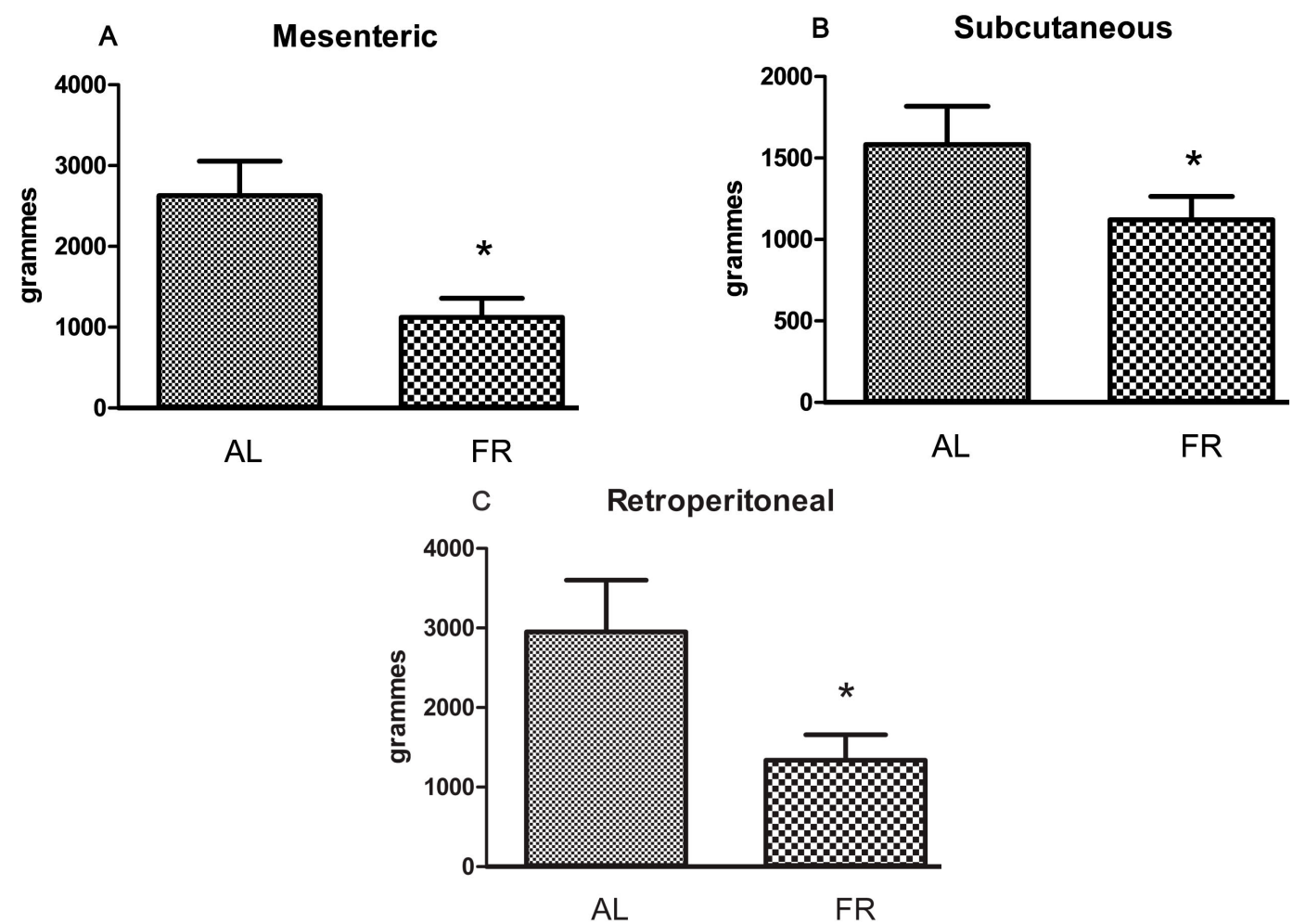

Fig. (4). The weight of adipose tissue from different regions, mesenteric (A), subcutaneous $(\mathbf{B})$ and retroperitoneal $(\mathbf{C})$, at the end of the experiment. Results are expressed as means \pm standard deviation (10 animals/group). $* \neq$ control group.

hormone, when in excess in the circulation (diabetes mellitus type 2), will play an important role by activating the lipogenic transcription factor SREBP (sterol regulatory elementbinding protein) $[42,43]$. The SREBPs directly activate the expression of approximately 30 genes dedicated to the synthesis and uptake of cholesterol, fatty acids, triglycerides and phospholipids and of NADPH, a cofactor required for the synthesis of these molecules [44, 45]. Though three SREBPs were found in the liver, SREBP-1c is preferentially more active by increasing the transcription of genes involved in fatty acid synthesis, including genes that encode for the enzymes acetyl-CoA carboxylase and fatty acid synthase. The first enzyme converts acetyl-CoA to malonyl-CoA and the second converts malonyl-CoA to palmitate [44] contributing to the accumulation of fat in the liver and consequently to the installation of nonalcoholic steatohepatitis (NASH).

\section{Hepatic Triglycerides}

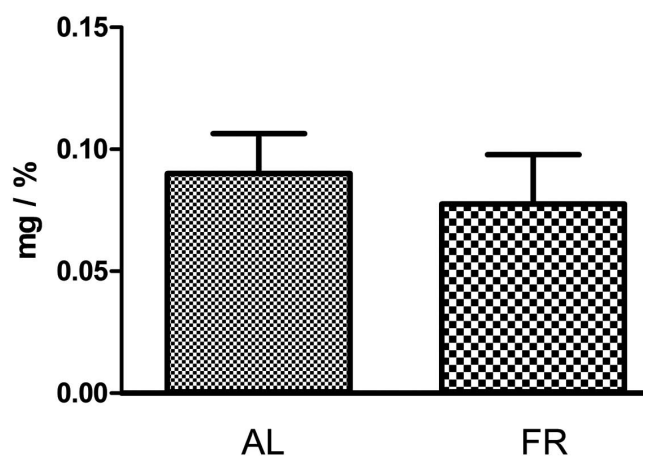

Fig. (5). The concentrations of fat in the livers at the end of experiment. Results are expressed as means \pm standard deviation (10 animals/group).
NASH is characterised by fat accumulation in the liver and can lead to inflammation in the organ until fibrosis occurs [3-7]. IR will contribute to the development of NASH; in individuals resistant to insulin, the SREBP-1c levels are elevated due to high levels of the hormone [46]. Similarly, the SREBP-1c levels are elevated in the livers of ob/ob mice $[47,48]$. Despite the presence of insulin resistance in peripheral tissues, insulin activates transcription of SREBP-1c in the livers of rats. The high levels of nuclear SREBP-1c increase the expression of lipogenic genes, fatty acid synthesis and an accumulation of triglycerides in the liver [48, 49]. In our study, four weeks were not sufficient for the development of IR, but it was seen that for a $1 \%$ decrease in body weight, insulin sensitivity increased $0.67 \%$ and hepatic fat accumulation decreased $0.67 \%$. This may be due to a decreased supply of calories from the dietary restriction, which leads to a reduced production of insulin by the pancreas. There is a consequential decrease in the activation of SREBPs in the adipose tissue and liver, thus reducing the amounts of fat substrate in these tissues [42, 44, 48, 49, 50].

\section{CONCLUSION}

From the observed results, we can conclude that four weeks were not sufficient for the development of IR and that dietary restriction, which does not cause malnutrition, improves insulin sensitivity and minimises the fatty accumulation on body and liver in both eutrophic rats.

\section{AUTHOR CONTRIBUTIONS}

All of the authors contributed to the study not only with the sample collections but also with the preparation of this manuscript. All of the authors have read and approved of the final version of this manuscript. 


\section{ACKNOWLEDGEMENTS}

The authors would like to thank the technicians from the Laboratory of Biodynamics, Department of Physical Education, UNESP, Rio Claro campus, Clarice Sibuya and José Roberto Rodrigues for their essential support. In addition, the authors would like to thank the Brazilian Council for Scientific and Technological Development (CNPq) and the State of São Paulo Research Foundation (FAPESP) for their financial support.

\section{CONFLICT OF INTEREST}

None declared.

\section{ABBREVIATIONS}

$\begin{array}{ll}\text { IR } & =\text { Insulin Resistance } \\ \text { TNF- } \alpha & =\text { Tumour Necrosis Factor } \\ \text { IRS-1 } & =\text { Insulin Receptor Substrate-1 } \\ \text { SREBP } & =\text { Sterol Regulatory Element-Binding Proteins } \\ \text { NAFLD } & =\text { Nonalcoholic Fatty Liver Disease } \\ \text { ITT } & =\text { Insulin Tolerance Test } \\ \text { Kitt } & =\text { Removal Rate of Serum Glucose }\end{array}$

\section{REFERENCES}

[1] Diehl AM. Nonalcoholic steatohepatitis. Sem Liver Dis 1999; 19; 221-9.

[2] Ludwig J, Viggiano TR, Mcgill DB, Oh BJ. Nonalcoholic steatohepatitis: Mayo Clinic experiences with a hitherto unnamed disease. Mayo Clin Proc 1980; 55: 434-8.

[3] Sheth SG, Fredric D, Chopra S. Nonalcoholic steatohepatitis. Ann Inter Med 1997; 137: 45.

[4] Mulhall BP, Ong JP, Younossi ZM. Non-alcoholic fatty liver disease: an overview. J Gastroenterol Hepatol 2002; 17:1136-43.

[5] Angulo P. Nonalcoholic fatty liver disease. N Engl J Med 2002; 346: $1221-31$.

[6] Alba LM, Lindor K. Review article: non-alcoholic fatty liver disease. Aliment Pharmacol Ther 2003; 17: 977-86.

[7] Utzschneider KM, Kahn SE. Review: The role of insulin resistance in nonalcoholic fatty liver disease. J Clin Endicrinol Metab 2006; 91: 4753-61.

[8] Burt AD, Mutton A, Day C. Diagnosis and interpretation of steatosis and steatohepatitis. Semin Diagn Pathol 1998; 15: 246-58.

[9] Schwimmer JB, Deutsch R, Rauch JB, Behling C, Newbury R, Lavine JE. Obesity, insulin resistance, and other clinicopathological correlates of pediatric nonalcoholic fatty liver disease. J Pediatr 2003; 143: 500-5.

[10] Louthan MV, Barve S, MCclain CJ, Joshi-Barve S. Decreased serum adiponectin: an early event in pediatric nonalcoholic fatty liver disease. J Pediatr 2005; 147: 835-8.

[11] Polovina S, Micić D. The influence of diet with reduction in calorie intake on metabolic syndrome parameters in obese subjects with impaired glucose tolerance. Med Pregl 2010; 63: 465-9.

[12] Reaven GM. Role of insulin resistance in human disease. Diabetes 1988; 37: 1595-600

[13] Wellen KE, Hotamisligil GS. Inflammation, stress, and diabetes. J Clin Invest 2005; 115: 1111-9.

[14] Pardee PE, Lavine JE, Schwimmer JB. Diagnosis and treatment of pediatric nonalcoholic steatohepatitis and the implications for bariatric surgery. Semin Pediatr Surg 2009; 18: 144-51.

[15] Socha P, Horvath A, Vajro P, Dziechciarz P, Dhawan A, Szajewska $\mathrm{H}$. Pharmacological interventions for nonalcoholic fatty liver disease in adults and in children: a systematic review. J Pediatr Gastroenterol Nutr 2009; 48: 587-96.

[16] Nobili V, Carter-Kent C, Feldstein AE. The role of lifestyle changes in the management of chronic liver disease. BMC Med 2011; 9: 70
Martin BJIS, Stuart MS, Mattson MP. "Control" laboratory rodents are metabolically morbid: Why it matters. Proc Natl Acad Sci USA 2010; 107(14): 6127-33

[18] Goodrick CL. Effects of long-term voluntary wheel exercise on male and female Wistar rats. I. Longevity, bodyweight, and metabolic rate. Gerontology 1980; 26: 22-33.

[19] Holloszy JO. Exercise increases average longevity of female rats despite increased food intake and no growth retardation. J Gerontol 1993; 48: B97-B100.

[20] Yu PB, Masoro EJ, Murata I, Bertrand HA, Lynd FT. Life span study of SPF fischer 344 male rats fed ad libitum or restricted diets: longevity, growth, lean body mass and disease. J Gerontol 1982; 37: $130-41$.

[21] Weindruch R, Walford RL, Fligiel S, Guthrie D. The retardation of aging in mice by dietary restriction: longevity, cancer, immunity and lifetime energy intake. J Nutr 1986; 116: 641-54.

[22] Weindruch R, Walford RL. Dietary restriction in mice beginning at 1 year of age: effect on life-span and spontaneous cancer incidence. Science 1982; 15: 1415-8.

[23] Heilbronn LK, Ravussin E. Calorie restriction and aging: review of the literature and implications for studies in humans. Am J Clin Nutr 2003; 78: 361-9.

[24] Mattson MP, Wan R. Beneficial effects of intermittent fasting and caloric restriction on the cardiovascular and cerebrovascular systems. J Nutr Biochem 2005; 16: 129-37.

[25] Guarente L. Sirtuins as potential targets for metabolic syndrome. Nature 2006; 444: 868-74

[26] Shalileh M, Shidfar F, Haghani H, Eghtesadi S, Heydari I. The influence of calcium supplement on body composition, weight loss and insulin resistance in obese adults receiving low calorie diet. J Res Med Sci 2010; 15: 191-201

[27] Moura LP, Chiyoda A, Teixeira CVL, et al. Effects of Exercise and Cinnamon Extract on Blood Chemistry of Type 1 Diabetic Rats. J Exerc Physiol Online 2010; 13: 4

[28] Botezelli JD, Moura RF, Dalia RA, et al. Exercise counteracts fatty liver disease in rats fed on fructose-rich diet. Lipids Health Dis 2010; 9: 116

[29] Lundbaek K. Intravenous glucose tolerance as a tool in definition and diagnosis of diabetes mellitus. Br Med J 1962; 3: 1057-513.

[30] Nogueira DM, Strufaldi B, Hirata MH, Abdalla DSP, Hirata RD. Métodos de bioquímica clínica. São Paulo: Pancast 1990.

[31] Almeida PBL, Mello MAR. Fetal/neonatl protein restriction, insulin action and glucose homeostasis in adult life: effects of fasting and cute exercise. Rev Bras Educ Fís Esporte 2004; 18: 17-30.

[32] Voltarelli FA, Camargo PB, Mello MAR, et al. The validity of the lactate minimum test adapted to rats. Med Sci Sports Exerc 2005; 37: 443.

[33] Gobatto CA, Kokubun E, Sibuya C, Mello MAR. Efeitos da desnutrição protéico calórica e do treinamento físico na produção de ácido lático em ratos machos adultos após teste de cargas progressivas. SBPC 1991; 43: 725-6.

[34] Kraemer WT, Volek JS, Clark KL, et al. Influence of exercise training on physiological and performance changes with weight loss in men. Med Sci Sports Exerc 1999; 21: 1320-9.

[35] Schutz Y. Macronutrient and energy balance in obesity. Metabolism 1995; 44: 7-11.

[36] Pereira LO, Francischi RP, Klopfer M, et al. Obesidade e sua implicações - ação da atividade física e controle nutricional. Rev Bras Nutr Clin 1999; 14: 9-17.

[37] Pritchett CE, Hajnal A. Obesogenic diets may differentially alter dopamine control of sucrose and fructose intake in rats. Physiol Behav 2011; 104: 111-6.

[38] Hermsdorff HHM, Monteiro JBR, Mourão DM, Leite MCT. Termogênese induzida pela dieta: uma revisão sobre seu papel no balanço energético e no controle de peso. Rev Bras Nutr Clin 2003; 18: 37-41.

[39] Barzilai N, Gupta G. Revisiting the role of fat mass in the life extension induced by caloric restriction. J Gerontol A Biol Sci Med Sci 1999; 54: 89-96

[40] Kissebah AH. Insulin resistance in visceral obesity. Int J Obes 1991; 15: 109-15.

[41] Bjorntorp P. Metabolic implications of body fat distribution. Diabetes Care 1991; 14: 1132-43.

[42] Horton ES. Metabolic aspects of exercise and weight reduction. Med Sci Sports Exerc 1985; 18: 10-8. 
[43] Ferre P, Foufelle. Fator de transcrição-SREBP e homeostase lipídica: perspectiva clínica. Horm Res 2007; 68: 72-82.

[44] Brown MS, Goldstein JL. The SREBP pathway: regulation of cholesterol metabolism by proteolysis of a membrane-bound transcription factor. Cell 1997; 89: 331-40.

[45] Sakakura Y, Shimano H, Sone H, et al. Sterol regulatory elementbinding proteins induce an entire pathway of cholesterol synthesis. Biochem Biophys Res Commun 2001; 286: 176-83.

[46] Carvalheira JBC, Zecchin HG, Saad MJA. Vias de sinalização da insulina. Arq Bras Endocrinol Metab 2002; 46(4): 419-25.

[47] Shimomura I, Bashmakov Y, Horton JD. Increased levels of nuclear SREBP-1c associated with fatty livers in two mouse models of diabetes mellitus. J Biol Chem 1999; 274: 30028-32.
[48] Shimomura I, Hammer RE, Ikemoto S, Brown MS, Goldstein JL. Leptin reverses insulin resistance and diabetes mellitus in mice with congenital lipodystrophy. Nature 1999; 401: 73-6.

[49] Anthonsen MW, Ronnstrand L, Wernstedt C, Degerman E, Holm C. Identification of novel phosphorylation sites in hormonesensitive lipase that are phosphorylated in response to isoproterenol and govern activation propertiesin vitro. J Biol Chem 1998; 273 215-21.

[50] Koubova J, Guarente L. How does calorie restriction work? Gen Dev 2003; 17: 313-21.

(C) de Moura et al.; Licensee Bentham Open

This is an open access article licensed under the terms of the Creative Commons Attribution Non-Commercial License (http://creativecommons.org/licenses/by-nc/3.0/) which permits unrestricted, non-commercial use, distribution and reproduction in any medium, provided the work is properly cited. 